\title{
Risk and Rationality
}

\author{
Shreya Shankar \\ National Law Institute University, Bhopal, India \\ Email: shreyashankar1013@gmail.com
}

How to cite this paper: Shankar, S. (2019). Risk and Rationality. Journal of Financial Risk Management, 8, 305-314.

https://doi.org/10.4236/jfrm.2019.84021

Received: November 27, 2019

Accepted: December 27, 2019

Published: December 30, 2019

Copyright $\odot 2019$ by author(s) and Scientific Research Publishing Inc. This work is licensed under the Creative Commons Attribution International License (CC BY 4.0).

http://creativecommons.org/licenses/by/4.0/

\begin{abstract}
Since time immemorial, people have made decisions, both big and small based on biased perceptions and faulty cognitive processes. Such perceptions and biases bore a positive correlation to the rate of survival of the individual for a large part of human history. This type of survival strategy owes its roots to the most primal coding in the human brain. While biases may have been a way of life in the past, the increasing complexity of human interactions has resulted in these biases that helped the survival of humans to cause more negative outcomes. Though history is replete with examples of healthcare and economic disasters due to such heuristics, individuals and theorists are often reluctant to make changes in their thinking and theories. This paper explores the biases that plague the risk management sector of the global economy. It primarily deals with four core biases that form the pillars that support the entire mental network of cognitive biases and seeks to identify proactive methods that advisors and investors can use in order to maximise their returns by neutralising the effect of these biases.
\end{abstract}

\section{Keywords}

Bias, Heuristic, Risk Profiler, Rational Profiling, Risk, Rationality, Financial

Risk, Investment Risk, Rational Choice, Economic Risk, Behavioral Economics

\section{Introduction}

Taking risks has been an inherent part of the human civilisation since time immemorial. From whether to consume a new variety of berries to whether to invest in a particular stock option, the element of dealing with everyday risk and analysing short term and long term impacts of such risks taken has a clear evolutionary basis (Robson, 1996). This evolutionary basis is important in that the cognitive biases that governed humanity's decision on what to eat and where to live continues to guide our decision on what to spend on and what to save through the binary choice model (Brennan \& Lo, 2011). However the circums- 
tances of economic and social decisions today are substantially different today than what it was in the past (Basiago, 1999). Using the same heuristics and cognitive biases that have been developed evolutionarily often results in less than optimal solutions (Allen \& Coole, 2012).

Additionally, classical economics make an assumption of rationality of decision making in humans (Blume \& Easley, 2007), who often behave in a manner that cannot be described as rational (Marschak, 1950). The models of consumption, production and utility are based on a number of axioms (Herstein \& Milnor, 1953) which, though convenient, often do not reflect the reality of ever fluctuating investment decisions made (Machulup, 1946). This shortcoming makes it difficult for the classical model to be applied effectively in the real world. In order to bridge the gap, newer economic models have been proposed (Kahneman \& Tversky, 1979).

The reason why these economic models must be reassessed in light of the evolutionary biases is twofold. Firstly, human beings are making increasingly more complex decisions with the same biases that they inherited from their ancestors who inhabited a less sophisticated world. Secondly, such faulty decision making has led to the general distrust of the investment industry itself. This has led to numerous people passing up on one of the biggest opportunities to improve their economic stature. In light, of these two statements, it becomes highly relevant in the present economic system, to decode the methods in which decision-making models lead to undesirable results.

This paper shall seek to analyse the axioms and assumptions of the classical model. It will then look at the four important heuristics of availability, representativeness, framing and overconfidence in the context of the prospect theory. The paper will also look at the way a risk profile of an individual is done by firms in the wealth management industry and analyse the advantages and the shortcomings of such a profile on the basis of heuristics and cognitive biases discussed earlier.

\section{Classical Theory}

The classical school of economics has been proposed and expanded on by great economists such as David Ricardo and Marshall. This brand of microeconomics developed during the industrial revolution, and hence carries with it the certain axioms and assumptions that drove the industrial revolution itself (Fine \& Leopold, 1990). Some of these assumptions continue to hold true in the modern world and have important implications in areas such as resource conservation (Colander, 1995). However, Marshallian observations of human behavior are generally based on the prime assumption of rationality (Blume \& Easley, 2007) which by and of itself has been disproved by multiple examples over the years (Marschak, 1950).

The rationality axiom gives rise to three other axioms of independence, invariance and dominance. Though the three axioms appeal to the immediate intel- 
lect, they often do not hold good in the real world.

The independence axiom refers to the assumption that, the introduction of a third variable will not affect the preference between two other variables or bundles (Neumann \& Morgenstern, 1953). Though an economic man (Zak, 2008) will adhere to such an assumption, most human beings tend to be influenced by the presentation of a third option. For example, a common marketing technique to influence a customer deciding between two goods with a small difference in price, to pick the more expensive option, is to present a third similar good that is significantly more expensive. This option may be irrelevant to the relative utility derived from the first two options due to the working of the certainty effect (Tversky \& Kahneman, 1986). This means that people tend to over weigh the movement from certainty to probability than a reduction from one probability to another (Li \& Chapman, 2009).

The invariance axiom (Richter, 1966) postulates that the order of presenting two or more commodities to an individual should not alter the relative utility derived from a bundle of those products. However, due to psychological concepts such as the primacy effect (Glenberg et al., 1980), this axiom often does not apply in real world situations. It is easiest to observe this exception to the invariance heuristic, in the hospitality industry. The order in which the menu is presented, and the quantum of food consumed prior to the presentation of the second option significantly impacts the utility of the other good in the bundle. For example, a person may prefer having a cookie after coffee, but may not feel the need to invest in a cup of coffee after the cookie. The framing heuristic that most human beings apply results in violations of this axiom.

The dominance axiom necessitates that "more is better" (Kreps, 1988). It assumes that a person will always want to obtain a bundle with more of both the commodities as compared to one with lessor of both commodities. The dominance effect falls in the real world to a phenomenon known as the disposition effect (Shefrin \& Statman, 1985). This refers to the likelihood of an investor to sell assets that have increased in value since they were bought and retain assets that have decreased in value since they were bought (Barberis \& Xiong, 2006). What this means is that, there is bias that leads to individuals evaluating the market value of a share based on their purchase price. This is detrimental as it causes sale of shares that are doing well and simultaneously leads to the clogging of the portfolio with non-performing shares due to the hope that the price will increase to meet the purchase price.

A combination of all the aforesaid axioms results in neglecting an important behaviour of human beings of loss aversion. Human beings often see losses as more damaging than a corresponding increase in their total wealth. In other words, a loss of certain amount would lead to a greater decrease in utility derived than a corresponding increase in utility gained if the same amount was gained (Tversky \& Kahneman, 1992). Additionally, humans are usually risk seeking over losses and risk averse over gains (Tversky \& Kahneman, 1984). The appreciation of this nuance leads us to the prospect theory of money utility. 


\section{Prospect Theory}

The prospect theory was developed by Tversky and Kahneman in response to the aforementioned classical theory. Apart from discounting the previous assumptions of the classical theory, the prospect theory also developed based on two important axioms-Regret theory (Loomes \& Sugden, 1982) and omission bias (Jonathan \& Ilana, 1994). These axioms refer to the general tendency of an individual to prefer to omit to take actions that have a probability of creating a loss for the individual. A person prefers to take no action and see his asset value decrease, as opposed to take action to the same effect, even if the probability of the asset value decreasing to the same effect is lower.

Based on these two principles, the expected utility curve of the prospect theory is significantly different compared to the expected utility curve of the classical theory. The latter starts from the origin and is concave, hence it is a function of absolute wealth (Neumann \& Morgenstern, 1953). However, the former is convex in the third quadrant, representing risk taking over losses and concave in the first quadrant, representing risk aversion over gains (Tversky \& Kahneman, 1984). The prospect theory also recognises that an increment in wealth is not a function of absolute wealth but a reference point (Kahneman \& Tversky, 1979).

\section{Biases and Heuristics}

In essence, the heuristics and cognitive biases that have led to the prospect theory are often a product of misinterpreting probability of the movement of the market in a certain direction or the happening or not happening of an event.

Individuals tend to perceive events that are widely reported or are sensationalised by the media as more likely to happen to them, even if they are one-off events that have a very low statistical probability of happening. This bias is known as the availability heuristic, (Esgate \& Groome, 2005) i.e., information that is widely available is considered as more probable than information that is not widely available but more common. This result in individuals making investments based on news headlines rather than market trends (Colman, 2009). The heuristic itself has an evolutionary basis (Haselton, 2009) because early man assessed threats based on the memory of those threats. Hence, the incidents easier to recall are usually considered as more likely to happen. Sensationalised news may result in vivid recall. Similarly, people tend to overweight occurrences that are more recent or occur more frequently (Manis et al., 1993). An example of such a bias affecting the rationality of decision making is the increase in the number of insurance subscriptions for destruction of property due to natural disasters after one of incident of such a disaster. This evidently a bad investment that is likely to have a very low probability of occurrence.

The way in which choices are presented often results in a different decision altogether. This form of a cognitive bias is known as framing or preference reversal and it violates the axiom of invariance (Shefrin \& Statman, 1985). Framing often relates to a misinterpretation of the point of reference (Tversky \& Kahne- 
man, 1981). Human beings often fail to update their point of reference after a gain or loss, especially in the market period. This leads to suboptimal decisions as the decisions made are based on the original reference point that is no longer relevant. This holds relevance to investments made by actively managing portfolios. New developments that are being made are not accounted for while making new investment decisions, leading to a disruption of the equilibrium. Buying additional insurance as add ons after paying a relatively high premium is an example of such an effect (Tversky \& Kahneman, 1981). The heuristic of framing may result in an undiversified portfolio as both the investment options are seen separately and not as a part of the total aggregate investments. Due to the endowment effect, (Roeckelein, 2006) individuals also tend to hold on to their current assets as it is perceived as more valuable. This is reflected through the practice of individuals refusing to sell assets that are no longer practically valuable. The rational behaviour to exhibit in this case would be to sell such properties to minimise maintenance costs and invest in higher paying assets. By countering this heuristic, a more diversified portfolio which is also flexible, can be achieved.

Framing also results in a number of other biases such as anchoring (Tversky \& Kahnenam, 1974) and money illusion (Fisher, 1928). Anchoring refers to a situation where the price of a stock option is based on the first price that is revealed. Given that most people do not value a product on their own, the first point of information is significant in determining the value of product subsequently. Hence, most showrooms place their most expensive options closest to the point of entry so that the rational decision making in the individual is impaired. Money illusion, on the other hand, is typically experienced if a person is given an increase in salary. The individual typically uses the reference point of his prior salary and does not account for the inflation rates, hence making suboptimal saving and investment choices.

Representativeness (Gilovich \& Savitsky, 1996) is a broader heuristic that explains human economic behaviour more fundamentally. It is often used to describe the behaviour of an individual based on a forced formation of pattern. An important implication of this while dealing with the wealth management industry is that the stock markets will eventually "regress to the mean". However, the true period of the business cycle and the true mean of such a cycle is unknown. This is caused by assuming patterns to be true, even if there is little data to support it (Tversky \& Kahnenam, 1974). Given, that there is no to little understanding on what the mean is, the search for such elusive "mean" leads to poor decision making. In particular, individuals tend to sell off high performing assets in the anticipation of such regression.

Lastly, humans generally tend to overweight data that supports their beliefs and underweight data that does not. This leads to the dual phenomenon of belief perseverance (Baumeister \& Vohs, 2007) and confirmation bias (Plous, 1993). Individuals in general and investment bankers in particular tend to believe that their personal actions led to the growth of an asset (Doukas \& Petmezas, 2007) as opposed to market phenomenon. This leads to over active trading and even- 
tual suboptimal results. These cognitive biases are often grouped under the category of the overconfidence heuristic (Pallier et al., 2002).

\section{Status of the Current Investment Profiler}

A risk profiler (Economic-Times, 2017) attempts to understand the risk appetite of an individual based on his current investible corpus, insurance holdings, current distribution of portfolio, investment objective, specific needs and the time horizon. A risk profiler additionally attempts to understand the expectations of return and the ability to stand by an investment during market fluctuations; it also attempts to understand the level of personal involvement in managing investments.

The first important aspect to be noted is that a risk profiler is a self-report measure and hence may not accurately reflect the behaviour patterns and the biases that underlie such a pattern. However, given that a profiler is a first step in the investment path, it gives a snapshot of the individual's current corpus and perceptions of the market. Behaviours and responses of the investor to market fluctuations are studied later by an advisor in order to overcome these cognitive biases.

By analysing the investment objective of the individual in light of the current investible corpus, the biases that dictate the specific behaviour of the individual can be discovered. As has been established previously in this paper, such biases may lead to suboptimal solutions. The recognition of biases prior to the making of investment decision can significantly improve the optimisation of results of investment. Often investors assume that the movement of an index is indicative of whether the specific investment will do well. This information is often obvious from their assessment of the expected quantum of growth. However, this often suffers from the gambler's fallacy (BBC, 2015), in that a smaller sample of individual companies is expected to show the same characteristics as the index as a whole. It is imperative for the advisor analysing the risk profile to point out this fallacy to avoid the burden of untenable expectations on the part of the investor.

This issue also points to the problem of time horizons in the market. Individuals, due to the overconfidence heuristic (BBC, 2015) tend to prefer to actively manage portfolios. However, over-management of portfolios may lead to a worse performance than the index, especially in the long run, as it prevents the natural course of the business cycle from evening out profits and losses. This is not indicative of management by a professional advisor. Hence depending on the professed level employment, individual investors must be counselled on the level of active management that is healthy for the general growth of the invested asset.

It is also important to understand that the kind of biases and stereotypes held varies from person to person. The differences in cognitive biases stem from personal experiences in the world of investment and hence it is important for the 
advisor to move beyond the risk profiler and understand the psychological profile of the individual in question. As the basis of an investment relationship is trust, it is important to understand the individual in a holistic sense and develop a unique relationship.

Another way of utilising the risk profiler is to understand how the individual responds to available information. A risk averse person generally overweighs negative trends in the market and takes protective steps. However, this may prove to be counter-productive as it gives no time for the market to apply self-corrective mechanisms. Such a profile can be handled by the advisor by countering such biases to improve the performance of the portfolio as a whole.

\section{Limitations of the Research}

As the investment industry proceeds to become increasingly globalised, the decisions involved have become more complex and the stakes involved in such decisions are higher and impact more people. Our evolutionary biases often provide us with very little assistance to navigate this maze. This paper provides a theoretical starting point to understand how biases work and what can be done to mitigate them.

It is, however, imperative to take this approach further in the office and meeting rooms of investment advisors and risk profilers in order to maximise the benefit of the global economy. In order to do so, further research in the area of how to avoid bias, even as a professional, is necessary. The paper functions from the point of view of fact, what will take the industry further is to make forays into understanding how millennia of cognitive structuring can be restructured to be more in line with the modern world.

\section{Conclusion}

It is a fundamental part of human nature to behave in accordance with certain behavioural characteristics and under most circumstances in day to day life, these characteristics help cope with the ever-changing topography of our surroundings. However, investment is one of the areas wherein these behavioural heuristics prove to be counterproductive. Given that these behavioral features are more or less ubiquitous, the role of risk profiler or investment banker to avoid these pitfalls becomes more pivotal.

It is unreasonable to build a model of investment on the assumption that human beings are rational individuals. In most cases, they simply fail to exhibit rational behaviour in real life, A more useful, albeit complicated model that accounts for human fallacies is in order. In a world that is moving towards investments as a source of income and funds for new ventures, it is important for those involved in the risk management sector to recognise the thought process and heuristics of their customers. This analysis goes far beyond questions on the goals and aspirations of the investor. In a sense, the technique used to derive a function of the internal mechanisms governing investment behavior is projec- 
tive.

However, amidst the subjectivity of individual behavior lies an objective metric of cognitive biases that most people despite their level of education fall prey to. The presence of this fact enables the development of a stable metric to assess potential investors.

\section{Conflicts of Interest}

The author declares that there were no conflicts of interest in writing this article.

\section{References}

Allen, M., \& Coole, H. (2012). Experimenter Confirmation Bias and the Correction of Science Misconceptions. Journal of Science Teacher Education, 23, 387-405. https://doi.org/10.1007/s10972-012-9277-0

Barberis, N., \& Xiong, W. (2006). What Drives the Disposition Effect? An Analysis of a Long-Standing Preference-Based Explanation. The National Bureau of Economic Research. https://doi.org/10.3386/w12397

Basiago, A. D. (1999). Economic, Social, and Environmental Sustainability in Development Theory and Urban Planning Practice. The Environmentalist, 19, 145-161. https://doi.org/10.1023/A:1006697118620

Baumeister, R. F., \& Vohs, K. D. (2007). Encyclopedia of Social Psychology. Newbury Park, CA: Sage Publications. https://doi.org/10.4135/9781412956253

BBC (2015). Why We Gamble Like Monkeys. https://www.bbc.com/future/article/20150127-why-we-gamble-like-monkeys

Blume, L. E., \& Easley, D. (2007). Rationality. New York: Palgrave Macmillan. http://tuvalu.santafe.edu/ leb/rat03.pdf https://doi.org/10.1057/978-1-349-95121-5_2138-1

Brennan, T. J., \& Lo, A. W. (2011). The Origin of Behavior. Quarterly Journal of Finance, 1, 55-108. https://doi.org/10.1142/S201013921100002X

Colander, D. (1995). Marshallian General Equilibrium Analysis. Eastern Economic Journal, 21, 281.

Colman, A. M. (2009). A Dictionary of Psychology (3rd ed.). Oxford: Oxford University Press.

Doukas, J. A., \& Petmezas, D. (2007). Acquisitions, Overconfident Managers and SelfAttribution Bias. European Financial Management Journal, 13, 531-577. https://doi.org/10.1111/j.1468-036X.2007.00371.x

Economic-Times (2017). What Is a Risk Profiler. https://economictimes.indiatimes.com/wealth/plan/what-is-risk-profiler/articleshow/5 9604396.cms?from $=\mathrm{mdr}$

Esgate, A., \& Groome, D. (2005). An Introduction to Applied Cognitive Psychology. London: Psychology Press.

Fine, B., \& Leopold, E. (1990). Consumerism and the Industrial Revolution. Social History, 15, 151-179. https://doi.org/10.1080/03071029008567764

Fisher, I. (1928). The Money Illusion. New York: Adelphi Company.

Gilovich, T., \& Savitsky, K. (1996). Like Goes with Like: The Role of Representativeness in Erroneous and Pseudo-Scientific Beliefs. Skeptical Inquirer, 20, 34.

Glenberg, A. M. et al. (1980). A Two-Process Account of Long-Term Serial Position Ef- 
fects. Journal of Experimental Psychology, 6, 355-369.

https://doi.org/10.1037/0278-7393.6.4.355

Haselton, M. G. (2009). Adaptive Rationality: An Evolutionary Perspective on Cognitive Bias. Social Cognition, 27, 733-763. https://doi.org/10.1521/soco.2009.27.5.733

Herstein, I. N., \& Milnor, J. (1953). An Axiomatic Approach to Measurable Utility. Econometrica, 21, 291-297. https://doi.org/10.2307/1905540

Jonathan, B., \& Ilana, R. (1994). Reference Points and Omission Bias. Organizational Behavior and Human Decision Processes, 59, 475-498.

https://doi.org/10.1006/obhd.1994.1070

Kahneman, D., \& Tversky, A. (1979). Prospect Theory: An Analysis of Decision under Risk. Econometrica, 47, 263-292. https://doi.org/10.2307/1914185

Kreps, D. M. (1988). Notes on Theory of Choice. Boulder, CO: Westview Press.

Li, M., \& Chapman, B. G. (2009). 100\% of Everything Looks Good: The Appeal of One Hundred Percent. Psychonomic Bulletin Review, 16, 156-162. https://doi.org/10.3758/PBR.16.1.156

Loomes, G., \& Sugden, R. (1982). Regret Theory: An Alternative Theory of Rational Choice under Uncertainty. Economic Journal, 92, 805-824.

https://doi.org/10.2307/2232669

Machulup, F. (1946). Marginal Analysis and Empirical Research. American Economic Review, 36, 519.

Manis, M., Jonides, J., Shelder, J., \& Nelson, T. (1993). Availability Heuristic in Judgments of Set Size and Frequency of Occurrence. Journal of Personality \& Social Psychology, 65, 448-457. https://doi.org/10.1037/0022-3514.65.3.448

Marschak, J. (1950). Rational Behavior, Uncertain Prospects, and Measurable Utility. Econometrica, 18, 111-141. https://doi.org/10.2307/1907264

Neumann, J. V., \& Morgenstern, O. (1953). Theory of Games and Economic Behavior (3rd ed.). Princeton, NJ: Princeton University Press.

Pallier, G. et al. (2002). The Role of Individual Differences in the Accuracy of Confidence Judgments. The Journal of General Psychology, 129, 257-299.

https://doi.org/10.1080/00221300209602099

Plous, S. (1993). The Psychology of Judgment and Decision Making. New York: McGraw Hill.

Richter, M. K. (1966). Invariance Axioms and Economic Indexes. Econometrica, 34, 739-755. https://doi.org/10.2307/1910096

Robson, A. J. (1996). A Biological Basis for Expected and Non-Expected Utility. Journal of Economic Theory, 68, 397-424. https://doi.org/10.1006/jeth.1996.0023

Roeckelein, J. E. (2006). Elsevier's Dictionary of Psychological Theories. Amsterdam: Elsevier Science.

Shefrin, H., \& Statman, M. (1985). The Disposition to Sell Winners Too Early and Ride Losers Too Long: Theory and Evidence. The Journal of Finance, 40, 777-790.

https://doi.org/10.1111/j.1540-6261.1985.tb05002.x

Tversky, A., \& Kahneman, D. (1981). The Framing of Decisions and the Psychology of Choice. Science, 211, 453-458. https://doi.org/10.1126/science.7455683

Tversky, A., \& Kahneman, D. (1984). Choices, Values, and Frames. American Psychologist, 39, 341-350. https://doi.org/10.1037/0003-066X.39.4.341

Tversky, A., \& Kahneman, D. (1986). Rational Choice and the Framing of Decisions. The Journal of Business, 59, S251-S278. https://doi.org/10.1086/296365 
Tversky, A., \& Kahneman, D. (1992). Advances in Prospect Theory: Cumulative Representation of Uncertainty. Journal of Risk and Uncertainty, 5, 297-323.

https://doi.org/10.1007/BF00122574

Tversky, A., \& Kahnenam, D. (1974). Judgment under Uncertainty: Heuristics and Biases. Science, 185, 1124-1131. https://doi.org/10.1126/science.185.4157.1124

Zak, P. J. (2008). Moral Markets: The Critical Role of Values in the Economy. Princeton, NJ: Princeton University Press. 